\title{
FEASIBILITY OF ABSTINENCE AS A PREVENTIVE STRATEGY FOR HIV/AIDS CONTROL IN THE UNIVERSITY STUDENT COMMUNITY IN KUMASI, GHANA
}

\author{
Y.A.K. Enuameh, E.N.L. Browne, E. Owusu-Dabo, E. Otupiri and A. Edusei \\ Department of Community Health, \\ School of Medical Sciences, \\ Kwame Nkrumah University of Science and Technology, \\ Kumasi, Ghana.
}

\begin{abstract}
HIV is spreading and the youth bear the brunt of its onslaught. Though abstinence until marriage is thought to be the most effective method of HIV prevention for the youth, others think it is ineffective. This study assessed the feasibility of abstinence in preventing HIV/AIDS spread among tertiary students of the KNUST. Study type was non- interventional, descriptive and design current cross- sectional. Study participants were selected by stratified sampling, followed by systematic sampling. A total of 300 participants were sampled. Seventy nine (79\%) (95\% CI, 73.9-83.8) said STIs could be avoided by abstaining from sex. Ninety six (96\%) (95\% CI, 93.5-98.3\%) said HIV could be acquired via sex. Ninety six (96\%) (95\% CI, 93.8- 98.5\%) of those who said HIV could be avoided said it could be done by abstaining from sex. Seventy two (72\%) were of the view that sex should start only after marriage. Sixty nine $69 \%$ (95\% CI, 63.3-74.4\%) said they would wait till after marriage to involve in sex. Sixty seven (67\%) (95\% CI, 60.7-72.1\%) were encouraged by peers to abstain from sex, Seventy four (74\%) (95\% CI, 68.5- 79.1\%) thought colleagues their age had premarital sex and $28 \%$ (95\% CI, 22.5-33.4\%) said they were pressured to have sex. Thirty one (31\%) (95\% CI, 25.6-36.7\%) of respondents were sexually experienced. There is the general view that HIV/AIDS spread among the youth can be reduced by abstaining from sex until marriage and that abstinence could and should be encouraged as a preventive strategy for HIV/AIDS.
\end{abstract}

Keywords:Abstinence, HIV/AIDS, Sex, Marriage

\section{INTRODUCTION}

HIV/AIDS is spreading menacingly worldwide and the youth are bearing the brunt (Senderowitz, 2002). Concerned citizens worldwide in the quest to control the disease are advocating various interventions. Prominent among them is ab- stinence- keenly promoted by religious organizations and conservatives including President Bush. In Burkina Faso, the National Catholic Committee and the Youth Wing of the Church focus on abstinence until marriage and the teaching of Christian values as ways to prevent HIV/ 
AIDS (AGI, 2004). In Ghana, most organizations focus on abstinence until marriage (Mayhew, 2004); examples are "Virgin Clubs" (AwusaboAsare et al., 2004). Abstinence is one of the three methods advocated for HIV/AIDS control, ABC i.e. Abstinence, Be faithful and Condom use. The main thrust of 'abstinence' is encouraging the youth to avoid sex till marriage.

Pioneered in the USA in 1981, abstinence only programs teach that abstaining from sex until marriage is the only effective method of HIV prevention (Human Rights Watch, 2005). Numerous U.S.-funded studies have shown these programs as ineffective at changing young people's sexual behaviours and that they are rather potentially harmful as they discourage the use of contraception (Senderowitz, 2002).

Currently, three federal programs [Adolescent Family Life Program, Abstinence Education Formula Block Grant Program and CommunityBased Abstinence Education Grants] fund abstinence-only education. Since 1997, these programs have been funded at over half a billion dollars (HIV Prevention Bulletin, 2003).

Though laudable, to most reproductive health experts, abstinence alone is a nonstarter in preventing HIV/ AIDS spread. In Switzerland abstinence only programs are said to be inefficient and ethically questionable (Michaud, 2003); as amplified in a review by DiCenso et al. (2002) "Primary prevention strategies evaluated did not delay the initiation of sexual intercourse".

The current study assesses the feasibility of abstinence as a strategy for the control of HIV/ AIDS in among students of KNUST.

\section{MATERIALS AND METHODS}

A non-interventional, descriptive study type was used. The study design was current cross sectional. Written (self administered) questionnaires were hand delivered to the respondents and collected between September 12 and 31, 2004. A structured questionnaire made up of open-ended, close-ended and pre-categorized questions was used as the main instrument for data collection. The study focused on young people between the ages of 15 and 24 years, who were studying at KNUST and living on campus. Due to the age structure of students in the university, those in the first and second years of study falling within the above age group were the ones eligible for the study.

The total population of first and second year students was 7,205 (KNUST, 2004). Using StatCalc (Epi Info statistical Software) with an expected frequency for knowledge of HIV transmission as $92 \%$, the worst acceptable frequency for the same parameter at $89 \%$ and a confidence level of $95 \%$, the sample size of students was arrived at as 301. Stratified sampling followed by systematic sampling was used to select respondents (i.e. students) for the study. The researchers used this approach with the aim of including students from all the departments and faculties in the study. The population of first and second year students in each department was made as a fraction of the total first and second year student population of the university. Based on these fractions, quotas were allotted to each faculty, after which systematic sampling was used to get the required sample. A list of first and second year students was taken from the faculties and depending on the quotas involved, each $\mathrm{n}^{\text {th }}$ student was chosen. A total of 300 students from various departments of the University were selected and each was given a questionnaire to answer.

Pre testing of questionnaires was done at the Nursing Training College, Kumasi. This enabled the sequence of certain questions to be revised and the introduction of pre categorized instead of close-ended questions in a number of instances. Research Assistants were in charge of data collection. They submitted the answered questionnaires to the Principal Investigator at the close of each day's work. These questionnaires were checked to ensure that each had been answered after which they were numbered.

Quantitative data collected was analysed and results were enumerated in percentages to enable

2 Journal of Science and Technology, Volume 27 no. 2, August, 2007 
comparative analysis. Analysis was done using EPI-INFO version 3.3 (CDC, Atlanta, USA).

\section{RESULTS AND DISCUSSION \\ Background Characteristics of Student \\ Respondents}

As shown in table 1, the mean age of respondents in years was 20.78 (range: 16 - 24 years). The median age at sexual debut among the current study participants was 18 years as was in the study by Karim et al. (2003). Respondents in the current study who had ever had sex were $30.9 \%$ (95\% CI, 25.6-36.7\%) i.e. $29.5 \%$ females and $31.5 \%$ males in contrast to $41 \%$ females and $36 \%$ males in the study by Karim et al. (2003) among the general population. Glover et al. (2003) noted that up to $52 \%$ of all respondents ( $56 \%$ females and $48 \%$ males) had ever had sexual intercourse in a study done in the general population. The study by Taffa et al. (2003) in Ethiopia came up with a finding similar to the current study: a third of subjects with more males (40.7\%) than females (23\%) reported previous sexual activity. Females in the current study were found to be abstaining from sex relatively better than their compatriots in the general population. This creates the impression that education redi- rects the energies of females away from sex much more than for males.

Mean number of partners after first sex was 1.69 (1.44 for females and 1.77 for males). 16 of the 86 sexually experienced respondents did not state the number of partners they had after their sexual debut. Of the sexually experienced respondents, $69.57 \%$ females and $68.25 \%$ males had more than one sexual partner after sexual debut. This is overly high as compared to $4 \%$ females and $11 \%$ males found in the general populace by Karim et al. (2003).

\section{Perceptions of STI and HIV/ AIDS}

From tables 2 and 3, abstaining from sex (abstinence) was seen by $79.1 \%$ (95\% CI, 73.9$83.8 \%$ ) of respondents as the way to avoid getting STIs, followed by the use of condoms $57.6 \%$ (95\% CI, 51.5-63.4\%), avoiding casual sexual partners $(32.4 \%)$, avoiding sex workers $(22.3 \%)$ and the use of non penetrative sex $(16.2 \%)$. Glover et al. (2003) noted that, two thirds of respondents mentioned consistent use of condoms and others abstinence, fidelity and avoiding sharing of needles as ways of avoiding STIs. As to how HIV/AIDS could be acquired, 96.4\% (95\% CI, 93.5-98.3\%) of respondents in the current

Table 1: Background Characteristics of Student Respondents

\begin{tabular}{|c|c|c|c|}
\hline Characteristics & $\begin{array}{c}\text { Total } \\
(\mathrm{N}=\mathbf{2 7 8}) \%\end{array}$ & $\begin{array}{c}\text { Male } \\
(\mathrm{N}=\mathbf{2 0 0}) \%\end{array}$ & $\begin{array}{c}\text { Female } \\
(\mathrm{N}=78) \%\end{array}$ \\
\hline 1. Mean Age of respondents (Years) & 20.78 & 20.01 & 20.23 \\
\hline 2. Median Age at Sexual Debut & 18.00 & 18.00 & 18.00 \\
\hline $\begin{array}{l}\text { 3. Mean no. of partners after } 1^{\text {st }} \text { sex } \\
\text { 4. } \% \text { Distributions }\end{array}$ & 1.69 & 1.77 & 1.44 \\
\hline a. Age Groups & & & \\
\hline $15-19$ & 28.8 & 23.6 & 41.8 \\
\hline $\begin{array}{l}20-24 \\
\text { b. Sex Life }\end{array}$ & 72.2 & 76.4 & 58.2 \\
\hline Ever Had Sex & 30.9 & 31.5 & 29.5 \\
\hline c. Partners $>1$ (in Sexually Experienced) & $68.61(\mathrm{n}=86)$ & $68.25\left(\mathrm{n}_{\mathrm{m}}=63\right)$ & $69.57\left(\mathrm{n}_{\mathrm{f}}=23\right)$ \\
\hline
\end{tabular}


Table 2: Perceptions on STI and HIV/AIDS

\begin{tabular}{lccc}
\hline \multicolumn{1}{c}{ Characteristics } & Total $(\mathbf{N}=\mathbf{2 7 8})$ \% & Male $(\mathbf{N}=\mathbf{2 0 0}) \mathbf{\%}$ & Female (N=78) \% \\
\hline 1. How to avoid getting STIs & 16.2 & 13.0 & 24.4 \\
Non penetrative sex & 0.7 & 0.5 & 1.3 \\
Using herbs & 57.6 & 55.0 & 64.1 \\
Use of condom & 79.1 & 82.0 & 71.8 \\
Abstinence & 32.4 & 33.5 & 29.5 \\
Avoiding casual partners & 22.3 & 22.0 & 23.1 \\
Avoiding sex workers & & & \\
2. Ever heard of the illness AIDS & 97.1 & 97.0 & 97.4 \\
Yes & 2.5 & 2.5 & 2.6 \\
No & & & \\
3. Do you believe AIDS exists & 98.6 & 99.0 & 97.4 \\
Yes & 1.4 & 1.0 & 2.6 \\
No & &
\end{tabular}

Table 3: Transmission of and Avoidance of HIV/ AIDS

\begin{tabular}{lccc}
\hline Characteristics & $\begin{array}{c}\text { Total } \\
\text { (N=278) \% }\end{array}$ & $\begin{array}{c}\text { Male } \\
\text { (N=200) \% }\end{array}$ & $\begin{array}{c}\text { Female } \\
\text { (N=78) \% }\end{array}$ \\
\hline 1. Ways via which a person can get AIDS & & & \\
Sexual intercourse & 96.4 & 96.0 & 97.4 \\
Sharing needles & 76.3 & 83.0 & 59.0 \\
Blood transfusion & 77.3 & 83.0 & 62.8 \\
Via breast milk & 41.4 & 45.5 & 30.8 \\
During pregnancy & 40.6 & 45.0 & 29.5 \\
Mother to child at birth & 81.3 & 82.5 & 78.2 \\
Touch of an infected person & 2.5 & 2.0 & 3.8 \\
Insect bites & 1.8 & 2.0 & 1.3 \\
2. Is there a way one can avoid AIDS? & & & \\
Yes & 98.2 & 98.5 & 97.4 \\
No & 0.0 & 0.0 & 0.0 \\
3. If yes to 5, then what can one do? & $(273)$ & $(197)$ & $(76)$ \\
Abstain from sex & 96.7 & 95.4 & 100 \\
Be faithful to partner & 78.8 & 80.2 & 75.0 \\
Partner being faithful & 57.5 & 60.9 & 48.7 \\
Avoid sharing needles & 61.9 & 67.0 & 48.7 \\
Avoid casual sex & 58.2 & 64.0 & 43.4 \\
Avoid contaminated blood & 54.6 & 61.4 & 36.8 \\
Use condoms & 61.9 & 60.9 & 64.5 \\
Avoid sex workers & 48.7 & 50.3 & 42.1 \\
Avoid non sterile blades & 50.5 & 54.8 & 39.5 \\
\hline
\end{tabular}

4 Journal of Science and Technology, Volume 27 no. 2, August, 2007 
study said it was through sexual intercourse, $81.3 \%$ said from mother to child at birth, $77.3 \%$ said via blood transfusions, $76.3 \%$ said through the sharing of un-sterilized needles and via breast milk of lactating mothers $(41.4 \%)$. Touch of an infected person and insect bites were seen as means of transmission by $2.5 \%$ and $1.8 \%$ of respondents respectively. Glover et al. (2003) in their study among the youth in Ghana found out that $96 \%$ of them said sexual intercourse, $83 \%$ said transmission from mother to baby and $71 \%$ said sharing needles were the means of transmitting HIV. Most of them said HIV could not be transmitted via hand shakes or sharing of cooking utensils (Glover et al., 2003). As many as $98.2 \%$ of respondents in the current study said were of the view HIV/AIDS could be avoided. Of that proportion, $97.6 \%$ (95\% CI, 93.8- 98.5\%) of them said this could be through abstaining from sex, $78.8 \%$ said it could be by being faithful to one's partner, $61.9 \%$ each thought it could by the use of condoms and avoiding the use of un-sterilized needles. Avoiding contaminated blood (54.6\%), avoiding non sterile blades $(50.5 \%)$ and avoiding sex workers $(48.7 \%)$ were among other ways of avoiding HIV/AIDS. In a study among adolescents in Benue State of Nigeria, abstinence $(88 \%)$, followed by condom use $(81 \%)$, and monogamy or mutual fidelity $(71 \%)$ were seen as the methods of preventing HIV/ AIDS (Alubo et al., 2002).

\section{Ideal Age for Sex and Marriage}

As is shown in tables 4 and 5, over two thirds of respondents said the ideal age for a girl to have sex was after marriage. The ideal age for a boy to have sex was seen by $71.2 \%$ of respondents as after marriage. The ideal age of marriage for girls and boys was seen by $65.1 \%$ and $65.5 \%$ respectively of respondents as between 20 and 30 years of age. As many as 69.1\% (95\% CI, 63.3$74.4 \%$ ) of respondents said they planned to wait till after marriage before they had sexual intercourse.

\section{Perception on Issues of Premarital Sex}

As is shown in tables 6 and 7, in the current study about three quarters of respondents disagreed with the notion that boys and girls should have sex before marriage. A Thai study found that $25 \%$ of men and $60 \%$ of women believed that men should never have sex before marriage. However, in the same study, abstinence before marriage is more strongly censured for women both by women (95\%) and men (60\%) (Shah, 1997). Double standards are exhibited on the issue of premarital sex. Premarital sexual activity is considered to be more acceptable for males than for females by both sexes (Brown et al. 2001). In some exceptional cases among secondary school students in Kampala, Uganda (70\%) and in Buenos Aires, Argentina (75- 85\%) both males and females agreed that premarital sexual activity was normal for both sexes (Brown et al. 2001). From results of the current study, two fifths of respondents said they had at one time or the other been encouraged to have sex with other members of their community by their unmarried friends. Two thirds of respondents said there was support from their friends to abstain from sex till marriage. A little over a quarter of respondents said they had at a point in time experienced pressure from their peers to engage in sex with others. Three quarters of respondents had the perception that couples of their age group engage in sexual activities prior to getting married. A third of respondents had ever discussed premarital sexual issues with their parents. Brown et al. (2001) saw a different phenomenon where issues like premarital sex were discussed more with peers than with parents. They however made the observation that where reproductive health information was received from the family, young females were more likely to consult their mothers.

\section{CONCLUSIONS}

Almost all the respondents were of the opinion that STIs and HIV/AIDS could be acquired via sex and best controlled by abstaining from sex first and foremost. Over two-thirds of the respon- 
Table 6: Perception on Issues of Premarital Sex

\begin{tabular}{lccc}
\hline Characteristics & Total $(\mathbf{N}=\mathbf{2 7 8})$ & Male $(\mathbf{N}=\mathbf{2 0 0})$ & Female $(\mathbf{N}=\mathbf{7 8})$ \\
\hline 1. A boy should have sex before marriage & & & \\
Agree & 18.7 & 18.5 & 19.2 \\
Disagree & 72.7 & 74.5 & 67.9 \\
Don't know & 8.6 & 7.0 & 12.8 \\
2. A girl should have sex before marriage & & & \\
Agree & 16.5 & 16.5 & 16.7 \\
Disagree & 76.3 & 77.0 & 74.4 \\
Don't know & 7.2 & 6.5 & 9.0 \\
\hline
\end{tabular}

Table 7: Support from Peers and Parents to Avoid Premarital Sex

\begin{tabular}{lccc}
\hline Characteristics & Total (N=278) & Male (N=200) & Female (N=78) \\
\hline 1. Unmarried girls encourage others to sex & & & \\
Yes & 29.1 & 30.5 & 25.6 \\
No & 28.1 & 28.0 & 28.2 \\
Don't know & 42.8 & 41.5 & 46.2 \\
2. Unmarried boys encourage others to sex & & & \\
Yes & 42.1 & 43.5 & 38.5 \\
No & 22.7 & 25.5 & 15.4 \\
Don't know & 35.3 & 31.0 & 46.2 \\
3. Have you ever been thus encouraged & & & \\
Yes & 40.3 & 40.5 & 39.7 \\
No & 54.3 & 53.0 & 57.7 \\
Don't know & 5.4 & 6.5 & 2.6 \\
4. There is support from friends to abstain from sex until & marriage & & \\
Yes & 66.5 & 63.0 & 75.6 \\
No & 22.7 & 25.5 & 15.4 \\
Don't know & 10.8 & 11.5 & 9.0 \\
5. There is pressure from friends to have sex & & & \\
Yes & 27.7 & 30.0 & 21.8 \\
No & 65.1 & 62.0 & 73.1 \\
Don't know & 7.2 & 8.0 & 5.1 \\
6. Do you think couples your age group have sexual relations before & marriage & \\
Yes & 74.1 & 78.0 & 64.1 \\
No & 4.3 & 4.0 & 5.1 \\
Don't know & 21.6 & 18.0 & 30.8 \\
7. Ever discussed with your parents issues of premarital sex & & \\
Yes & 31.7 & 28.5 & 39.7 \\
No & 61.9 & 64.0 & 56.4 \\
Don't know & 6.5 & 7.5 & 3.8 \\
\hline
\end{tabular}

6 Journal of Science and Technology, Volume 27 no. 2, August, 2007 
Table 4: Ideal Age for Sex and Plans for Future Sex

\begin{tabular}{lccc}
\multicolumn{1}{c}{ Characteristics } & $\begin{array}{c}\text { Total } \\
\text { (N=278) }\end{array}$ & $\begin{array}{c}\text { Male } \\
(\mathbf{N}=\mathbf{2 0 0})\end{array}$ & $\begin{array}{c}\text { Female } \\
(\mathbf{N}=\mathbf{7 8})\end{array}$ \\
\hline 1. Ideal age for a girl to have sex & & & \\
Between 10 and 20 years of age & 9.4 & 10.5 & 6.4 \\
Above 20 years of age & 2.5 & 4.0 & 5.1 \\
After marriage & 72.3 & 70.0 & 74.4 \\
Other & 1.4 & 0.5 & 2.6 \\
Don't know & 14.4 & 15.0 & 11.5 \\
2. Ideal age for a boy to have sex & & & \\
Between 10 and 20 years of age & 9.4 & 10.5 & 6.4 \\
Above 20 years of age & 4.3 & 4.0 & 5.1 \\
After marriage & 71.2 & 70.0 & 74.4 \\
Other & 1.1 & 0.5 & 2.6 \\
Don't know & 14.0 & 15.0 & 11.5 \\
3. Plans for sexual intercourse in the future & & & \\
I plan to wait until marriage & 69.1 & 68.5 & 70.5 \\
I plan to have sex as soon as possible & 2.2 & 3.0 & 0.0 \\
I plan to have sex when my partner wants it & 2.2 & 2.5 & 1.3 \\
I plan to wait until I find someone I love & 5.0 & 5.5 & 3.8 \\
I plan to have sex at the least opportunity & 1.1 & 1.0 & 1.3 \\
I plan to wait till I'm at least 17 & 0.7 & 0.5 & 1.3 \\
I plan to wait till I'm at least 19 & 1.8 & 2.5 & 0.0 \\
You can't plan for sex, it just happens & 13.7 & 11.5 & 19.2 \\
None of the above & 4.3 & 5.0 & 2.6 \\
\hline
\end{tabular}

Table 5: Ideal age for Marriage

\begin{tabular}{lccc}
\hline Characteristics & $\begin{array}{c}\text { Total } \\
\text { (N=278) }\end{array}$ & $\begin{array}{c}\text { Male } \\
(\mathbf{N = 2 0 0})\end{array}$ & $\begin{array}{c}\text { Female } \\
(\mathbf{N = 7 8})\end{array}$ \\
\hline 3. The ideal age for a girl to get married & & & \\
15 to 20 years of age & 7.2 & 9.0 & 2.6 \\
20 to 30 years of age & 65.1 & 65.0 & 65.4 \\
Above 30 years of age & 0.0 & 0.0 & 0.0 \\
Other & 5.4 & 3.5 & 10.3 \\
Don't know & 22.3 & 22.5 & 21.8 \\
4. The ideal age for a boy to get married & & & \\
15 to 20 years of age & 0.7 & 1.0 & 0.0 \\
20 to 30 years of age & 65.5 & 70.0 & 53.8 \\
Above 30 years of age & 5.0 & 2.5 & 11.5 \\
Other & 5.4 & 3.5 & 10.3 \\
Don't know & 23.4 & 23.0 & 24.4 \\
\hline
\end{tabular}


dents said the ideal age/ time for both boys and girls to have sex was after marriage. The ideal age for marriage was seen by about two-thirds of respondents as between 20 and 30 years. A little over two-thirds of students said they would wait till marriage to have sex.

More than two-thirds of respondents were against premarital sex for both boys and girls.

On the whole the study participants were against premarital sex and thought that abstinence was the best way of avoiding STIs and HIV/AIDS in particular. Abstinence therefore could be a feasible strategy in combating the spread of HIV/ AIDS among the student population of KNUST.

\section{REFERENCES}

AGI (2004). "Adolescents in Burkina Faso: Sexual and Reproductive Health." Research in Briefs; 4: 3. New York and Washington.

DiCenso, A., Guyatt, G., Willan, A. and Griffith, L. (2002). "Interventions to Reduce Unintended Pregnancies among Adolescents: Systematic Review of Randomized Controlled Trials." BMJ;324: 1426 (Downloaded from bmj.com on September $10,2005)$

Alubo, O., Oyediran, K. and Odiachi, A. (2002). Adolescent Sexuality and Reproductive Health in Benue State, Nigeria. CEDPA/ Nigeria

Awusabo-Asare, K., Abane, A. and KumiKyereme, A. (2004). "Adolescent Sexual and Reproductive Health in Ghana: A Synthesis of Research Evidence." Occasional Report (AGI) ;13; 25. New York and Washington

Brown, A., Jejeebhoy, S.J., Shah, I. and Yount, K.M. (2001). Sexual Relations among Young People in Developing Countries: pp 33- 38. Geneva: WHO (WHO/RHR/01.8, 2001)

Glover, E.K., Bannerman, A., Pence, B.W., Jones, H., Miller, M., Weiss, E. and Ner-
quaye-Tetteh J. (2003). "Sexual Health Experiences of Adolescents in Three Ghanaian Towns." International Family Planning Perspectives; 29 (1): 32-40

HIV Prevention Bulletin (2003). Focus on: HIV/ AIDS and GLBTQ Youth Gay, Lesbian, Bisexual, Transgender and Questioning (GLBTQ) Youth in the United States, NASTAD, Washington DC

Human Rights Watch (2005). "The Less They Know, the Better. Abstinence-Only HIV/ AIDS Programs in Uganda." HRW 17 (4 A): 1-79.

Karim, A. M., Magnani, R.J., Morgan, G.T. and Bond K.C. (2003). "Reproductive Health Risk and Protective Factors among Unmarried Youth in Ghana." International Family Planning Perspectives; 29 (1): 14-22

Mayhew Susannah (2004). Sexual and Reproductive Health in Ghana and the Role of Donor Assistance. A Case Study. Progress and Promises, Trends in International Assistance for Reproductive Health and Population (Population Action International). Pp.37, Washington. D.C.

Michaud, Pierre-Andre' (2003). "Prevention and Health Promotion in School and Community Settings: A Commentary on the International Perspective." Journal of Adolescent Health; 33: 219-225

Senderowitz J. (2002). "Securing the Future for Adolescents and the Youth". Congressional Briefing at Longworth House Office Building, Room 1539, October 24, 2002. (http:// www.globalhealth.org/news/article/2393)

Shah, I. (1997). Context, Needs and Perspectives. HRP's Annual Technical Report: pp 25. Geneva: UNDP/ UNFPA/ WHO

Taffa, N., Sundby, J. and Bjune, G. (2003). "Reproductive Health Perceptions, Beliefs and Sexual Risk-taking among Youth in Addis Ababa, Ethiopia." Patient Education and Counselling; 49 (2): 165-169.

8 Journal of Science and Technology, Volume 27 no. 2, August, 2007 